\title{
Multicomponent TiNi-based shape memory alloys: General considerations and selection rules for an initial precursor amorphous state
}

\author{
V. Kolomytsev, M. Babanly, R. Musienko, A. Sezonenko, P. Ochin ${ }^{1}$, A. Dezellus ${ }^{1}$, \\ P. Plaindoux ${ }^{1}$, R. Portier ${ }^{1,2}$ and Ph. Vermaut ${ }^{1,2}$
}

IMP NASU, 36 Vernadskogo Blvd., Kyiv, Ukraine

${ }^{1}$ CECM CNRS, 15 rue Georges Urbain, 94407 Vitry-sur-Seine, France

${ }^{2}$ ENSCP, 11 rue Pierre et Marie Curie, 75231 Paris, France

\begin{abstract}
General considerations, which concern the development of new multicomponent shape memory alloys in an initial amorphous state, are discussed. The selection rules for the chemical compositions appropriate for production of both amorphous and potentially shape memory alloys are proposed on a basis of well known three "golden rules" and statements regarding the shape memory phenomena. The production and characterisation of the "AB"-type series amorphous potentially shape memory alloys with "A" $=(\mathrm{Ti}, \mathrm{Hf}, \mathrm{Zr}), " \mathrm{~B} "=(\mathrm{Ni}, \mathrm{Cu}, \mathrm{Co}, \mathrm{Ag}, \mathrm{Pd}, \mathrm{Al})$ and the "A:B" ratio varied as 45:55, 50:50 and 55:45 are discussed. The material structure was followed by $X$ ray diffraction and the thermodynamic properties and thermal stability were studied by Differential Scanning Calorimetry. Various heat treatments regimes have been explored for the formation of appropriate microstructures to demonstrate the shape memory property.
\end{abstract}

\section{INTRODUCTION}

Recently, the polycrystalline shape memory alloys (SMA) are increasingly used in a wide range of applications in mechanics, electrotechnics, medicine, etc. However, only a limited number of the polycrystalline SMA has appropriate cold-workability properties for production in a form of sheets, wires, tubes, others. That is the reason why a great attention is continuously paid to the development of the non-conventional production technologies like powder metallurgy, rapid solidification, physical vapour deposition, etc. due to the possibility to receive the final product in a form close to the engineering requirements.

Our intention is to develop by means of non-conventional techniques, new multicomponent alloys initially in the amorphous state. Since the bulk amorphous materials demonstrate an extremely large deformation (above $15000 \%$ ) obtained in the supercooled liquid region [1,2], bulk amorphous state can be used as the precursor for forming of materials able to demonstrate the shape memory phenomena after an appropriate crystallisation and heat treatment.

In this article, general considerations with respect to selection of the chemical compositions, which are appropriate both for the good amorphization and for the shape memory phenomena, are described and verified on a basis of a set of experimental data obtained from multiple produced materials.

\section{SELECTION OF THE CHEMICAL COMPOSITION OF THE MULTICOMPONENT ALLOYS AND EXPERIMENTAL PROCEDURE}

The reference binary $\mathrm{Ti}-\mathrm{Ni}$ SMAs are typical representatives of the transition metal A:B type compounds. In bulk material condition, they undergo the B2-B19' or B2-R-B19' martensite transformations. The main factors influencing the characteristics of the martensite tranformation temperatures and functional properties are the chemical composition and microstructure, i.e. grain sizes, presence and distribution of precipitates, etc.

It is widely stated $[3,4,5,6,7]$ that the introduction of a small quantity of the third and fourth transition metal elements acts additionally on the martensite transformation temperatures, usually shifting them to the lower temperature interval with the rate depending on the type/nature of an individual element. Introduction of a bigger quantity (mostly, above 2-5 at.\%) of alloying elements generally results in formation of "a new matter" corresponding to the multicomponent solid solution. In this case, introduction of the betha-phase stabilizers (like $\mathrm{Cr}, \mathrm{Mn}, \mathrm{Fe}, \mathrm{Co}, \mathrm{Mo}, \mathrm{Tc}, \mathrm{Ru}, \mathrm{Rh}, \mathrm{W}, \mathrm{Re}, \mathrm{Os}, \mathrm{Ir}$ ) usually results in further decrease of the martensite transformation temperatures or even to full supression of the martensite transformation. On the contrary, introduction of the elements from the very beginning $(\mathrm{V}, \mathrm{Zr}, \mathrm{Y}, \mathrm{Nb}, \mathrm{Hf}$, $\mathrm{Ta})$ or from the end $(\mathrm{Cu}, \mathrm{Pd},(\mathrm{Ag}), \mathrm{Pt},(\mathrm{Au}))$ of each transition metal series often result in the increase of the martensite transformation temperatures (the degree of the increase to be more higher for 
elements from the end of each transition metal series than from the beginning $[8,9])$. Such multicomponent alloys are also important for production of amorphous phases because of the three wellknown "golden rules" which favor the glass forming ability [2]:

1. the number of the elements should be 3 at least.

2. the relative difference of main element atomic radii should be more than $12 \%$.

3. large negative mixing energy of the different atomic pair formation.

The reference multicomponent alloys of the A:B type (Ti50Ni50) are formed with "A" $=(\mathrm{Ti}, \mathrm{Zr}, \mathrm{Hf})$ and "B"=(Ni, Cu $): \mathrm{Ti}_{50}\left(\mathrm{Ni}_{25} \mathrm{Cu}_{25}\right), \mathrm{Ti}_{50}\left(\mathrm{Ni}_{18} \mathrm{Cu}_{32}\right),\left(\mathrm{Ti}_{32} \mathrm{Zr}_{18}\right) \mathrm{Ni}_{50},\left(\mathrm{Ti}_{32} \mathrm{Hf}_{18}\right) \mathrm{Ni}_{50}$. Substitution of $\mathrm{Zr}$ and $\mathrm{Hf}$ instead of $\mathrm{Ti}$ increases the martensite transformation temperatures. Introduction of $\mathrm{Co}, \mathrm{Al}, \mathrm{Pd}, \mathrm{Ag}$ instead of $\mathrm{Ni}$ and/or $\mathrm{Cu}$ has been chosen according to the golden rules. Be and $\mathrm{Y}$ substituted on $\mathrm{A}$ and $\mathrm{B}$ sites are described in another paper (this session). Other compositions with the ratio " $\mathrm{A} / \mathrm{B} "=45: 55$ and 55:45 have also been examined. Most of the bulk alloys demonstrate shape memory property due to the reversible martensite transformation in the $\left(-150^{\circ} \mathrm{C},+270^{\circ} \mathrm{C}\right)$ temperature range.

The alloy ingots ( 25 and $40 \mathrm{~g}$ weight) were prepared by induction melting in levitation by means of an inductive water cooled copper crucible under an helium atmosphere. Rapidly solidified ribbons (of thickness varied from 30 up to 60 microns) were prepared by the planar-flow melt spinning technique with eperimental conditions as-follow: copper based wheel with a velocity $=20 \mathrm{~m} / \mathrm{s}$, ejection pressure 200 $\mathrm{hPa}$ under a 1 bar helium atmosphere. Simple heating steps, $\left\{25^{\circ} \mathrm{C} \rightarrow\left(570-600^{\circ} \mathrm{C}\right), 1^{\prime}\right\}$, has been used to transform the amorphous ribbon into the crystalline state and restore the martensite transformation. Despite such a procedure, the martensite transformation often was not observed and various heat treatment regimes were to be used in the $\left(400^{\circ} \mathrm{C} \div 900^{\circ} \mathrm{C}\right)$ range. Thermal stability and thermodynamic properties were studied by the Differential Scanning Calorimetry in temperature range $\left(-150^{\circ} \mathrm{C}\right.$, $+600^{\circ} \mathrm{C}$ ).

\section{RESULTS AND DISCUSSION}

We report here partial results which concern structural, thermodynamic and crystallisation kinetics of alloys from the "A:B"=50:50 and 55:45 series.

Figure 1 represents typical DSC curves obtained in the cooling/heating cycles through the martensite transformation range for $\mathrm{Ti}_{32} \mathrm{Hf}_{18} \mathrm{Ni}_{45} \mathrm{Cu}_{5}$ and $\mathrm{Ti}_{32} \mathrm{Hf}_{18} \mathrm{Ni}_{35} \mathrm{Cu}_{15}$ in the bulk state with high transformation temperatures for the alloy with 5 at. \% of copper.

Fig. 1: DSC in the cooling/heating cycle for $\mathrm{Ti}_{32} \mathrm{Hf}_{18} \mathrm{Ni}_{45} \mathrm{Cu}_{5}$ and for $\mathrm{Ti}_{32} \mathrm{Hf}_{18} \mathrm{Ni}_{35} \mathrm{Cu}_{15}$ samples.

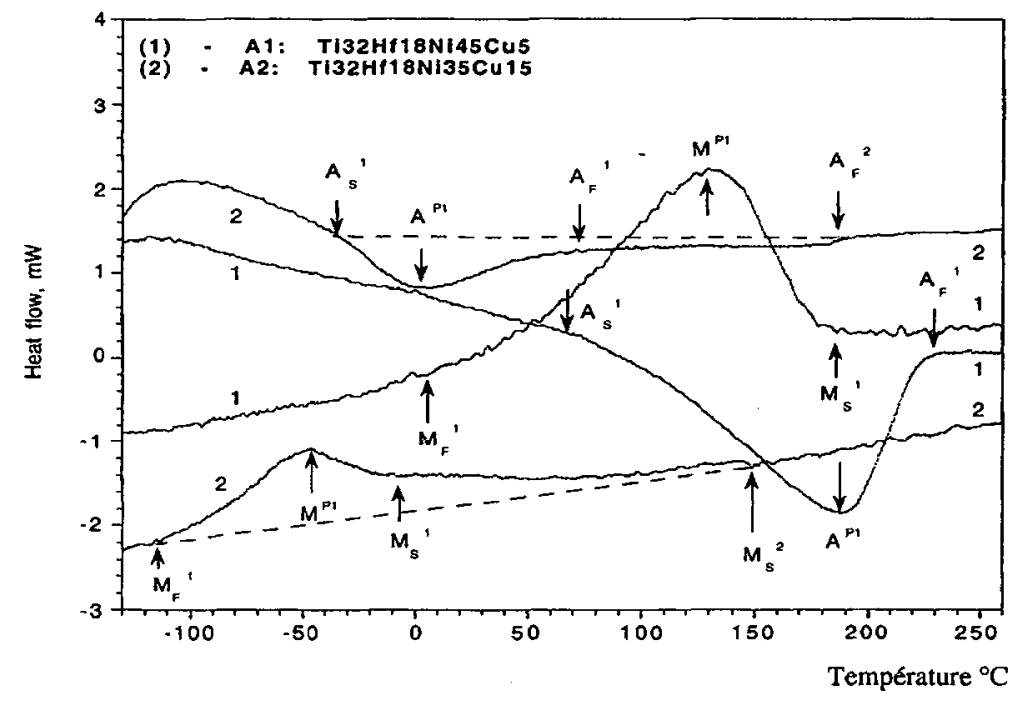

A systematic investigation of this strong dependence between chemical composition and transformation characteristic has been performed and the resultant « diagrams » of the martensite transformations on cooling in the ternary $\mathrm{TiNiCu}$ and quarternary $\mathrm{TiHfNiCu}$ alloys are shown in figure 2 . We have plotted the temperature of the maximum of the heat flow associated with the martensite transformation. There is a composition range where two successive martensitic transformations take place. For the ternary $\mathrm{TiNiCu}$ system, the $\mathrm{B} 2<=>\mathrm{B} 19^{\prime}$ transformation sequence changes to the $\mathrm{B} 2<=>\mathrm{B} 19<=>\mathrm{B} 19^{\prime}$ one 
approximately for compositions around $10 \mathrm{at} \% \mathrm{Cu}$. This alloy is not so much sensitive to the microstructural state since the temperature ranges of the martensite transformation are very closed for the as-cast bulk material and after homogenisation at $900^{\circ} \mathrm{C}$ for 1 hour. This characteristic has also been observed for rapidly solidified ribbons after crystallisation.
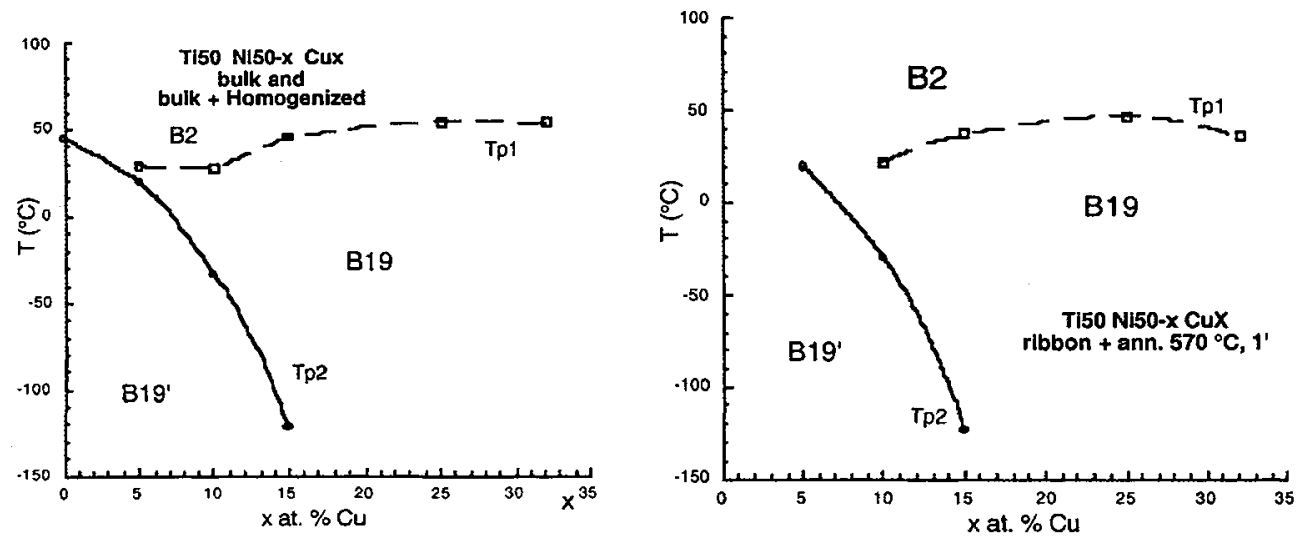

Fig 2 : Cu content effect on phase transformation for $\mathrm{Ti}_{50} \mathrm{Ni}_{50-x} \mathrm{Cu}_{x}$ as-cast, annealed bulk and rapidly solidified samples.

For quarternary $\mathrm{TiHfNiCu}$, this martensite transformation diagram is similar to the ternary TiNiCu alloys but at higher temperatures, which makes them very interesting (Fig. 3). These alloys are more sensitive to the microstructural states with some difference between the bulk alloy and after heat treatment.
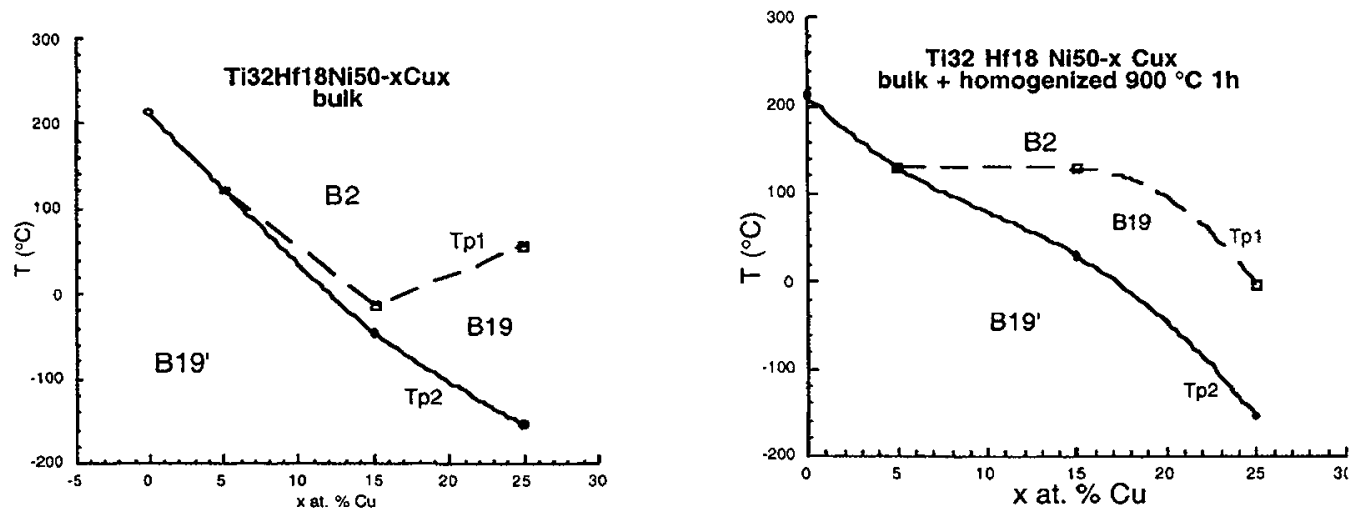

Fig. 3: $\mathrm{Cu}$ content effect on phase transformation for the $\mathrm{Ti}_{32} \mathrm{Hf}_{18} \mathrm{Ni}_{50-x} \mathrm{Cu}_{\mathrm{x}}$ as-cast bulk and annealed bulk samples.

The production of ribbons by planar flow casting for the $\mathrm{Ti}_{32} \mathrm{Hf}_{18} \mathrm{Ni}_{50-x} \mathrm{Cu}_{x}$ series has given a mixture of amorphous and crystalline phases for $\mathrm{Ti}_{32} \mathrm{Hf}_{18} \mathrm{Ni}_{50}$ and $\mathrm{Ti}_{32} \mathrm{Hf}_{18} \mathrm{Ni}_{45} \mathrm{Cu}_{5}$, the other compositions being fully amorphous (see table 1 for some general considerations and fig. 4 for Xray diffraction patterns).

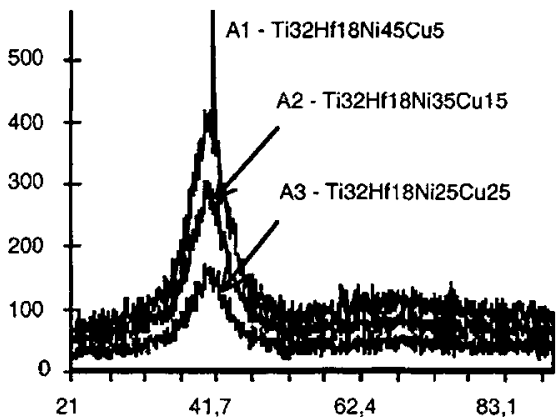

Fig. 4 : X-ray diffraction patterns for rapidly solidified alloys of the $A: B=50: 50$ series with $\mathrm{Cu}$ substituted on the B site. 
Other rapidly solidified alloys, $\mathrm{Ti}_{32} \mathrm{Zr}_{18} \mathrm{Ni}_{30}$ and $\mathrm{TiNiCu}(5 \rightarrow 15)$ of the "A:B"=50:50 series were found to be a mixture of the amorphous and crystalline (B2-type) microstructure components. The volume ratio between the crystalline and amorphous microstructure components is the highest in the binary alloy (no amorphous !) and continuously decreases with the number of constituent elements in a sequence as follows: TiHfNi, TiZrNi, TiNiCu $(5 \rightarrow 15)$, TiHfNiCu. The mean grain size in the crystalline part of the ribbons seems to be large enough since the reversible martensite transformation has been detected by DSC before crystallisation thermal treatment.

Table 1 : Some thermodynamic and structural characteristics for the $A: B=50: 50$ series alloys with $C u$ substituted on $B$ sites.

\begin{tabular}{|c|c|c|c|c|c|}
\hline Nominal Composition & TQuench. & Condition & $M P,{ }^{\circ} \mathrm{C}$ & $A P,{ }^{\circ} \mathrm{C}$ & Structures XRD \\
\hline Ti32Hf18Ni5O & 1300 & $\begin{array}{c}\text { Bulk } \\
\text { Homogenized } \\
\text { Ribbon } \\
\text { Ribbon, } 570^{\circ} \mathrm{C}, 1^{\prime}\end{array}$ & \begin{tabular}{|c|}
212 \\
212,4 \\
140 \\
138 \\
25 \\
\end{tabular} & $\begin{array}{l}253 \\
258 \\
212 \\
210 \\
105\end{array}$ & $\begin{array}{c}\mathrm{B} 19^{\prime} \\
\mathrm{B}^{\prime} 9^{\prime} \\
\mathrm{B} 2+\mathrm{B}^{\prime} 19^{\prime}+\mathrm{A} \\
\text { Two } \mathrm{B} 2<->\mathrm{B}^{\prime} 9^{\prime}\end{array}$ \\
\hline Ti32Hf18Ni45Cu5 & 1296 & $\begin{array}{c}\text { Bulk } \\
\text { Homogenized } \\
\text { Ribbon } \\
600^{\circ} \mathrm{C}, 1^{\prime}:(\mathrm{dT} / \mathrm{dt})=10^{\circ} \mathrm{C} / \mathrm{min} \\
600^{\circ} \mathrm{C}, 1^{\prime}:(\mathrm{dT} / \mathrm{dt})=100^{\circ} \mathrm{C} / \mathrm{min}\end{array}$ & \begin{tabular}{|c|}
122,2 \\
130,2 \\
-18 \\
68,8 \\
$-10,5$ \\
72,2 \\
$-12,7$ \\
\end{tabular} & \begin{tabular}{|c|}
178 \\
191,8 \\
59,5 \\
115 \\
74 \\
121 \\
68,8 \\
\end{tabular} & 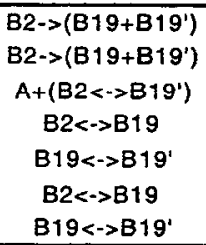 \\
\hline $\mathrm{Ti} 32 \mathrm{Hf} 18 \mathrm{Ni35Cu} 15$ & 1285 & $\begin{array}{c}\text { Bulk } \\
\text { Homogenized } \\
\text { Ribbon } \\
\text { Ribbon, } 570^{\circ} \mathrm{C}, 1^{\prime}\end{array}$ & \begin{tabular}{|c|}
-8 \\
-46 \\
130 \\
30 \\
no MT \\
no $M T$ \\
\end{tabular} & $\begin{array}{l}2,1 \\
70\end{array}$ & $\begin{array}{c}\mathrm{B} 2<->\mathrm{B} 19 \\
\mathrm{~B} 19<->\mathrm{B} 19^{\prime} \\
\mathrm{B} 2<->\mathrm{B} 19 \\
\mathrm{~B} 19<->\mathrm{B}^{\prime} 9^{*} \\
\mathrm{~A} \\
\mathrm{~B} 2+\mathrm{T} i 2 \mathrm{Ni}\end{array}$ \\
\hline Ti32Hf18Ni25Cu25 & 1300 & $\begin{array}{c}\text { Bulk } \\
\text { Homogenized } \\
\text { Ribbon } \\
\text { Ribbon, } 570^{\circ} \mathrm{C}, 1^{\prime} \\
\end{array}$ & \begin{tabular}{|c|}
57,4 \\
-155 \\
-2 \\
-155 \\
no MT \\
no MT \\
\end{tabular} & $\begin{array}{r}78 \\
186 \\
-58\end{array}$ & $\begin{array}{c}B 2+B 19 \\
B 19<->B 19^{\prime} \\
B 2<->B 19^{\prime} \\
B 2<->B 19^{\prime} \\
A\end{array}$ \\
\hline Ti32Hf18Ni15Cu35 & 1200 & $\begin{array}{c}\text { Bulk } \\
\text { Ribbon } \\
\text { Ribbon, } 570^{\circ} \mathrm{C}, 1^{\prime}\end{array}$ & $\begin{array}{l}\text { no } M T \\
\text { no } M T \\
\text { no } M T\end{array}$ & & A \\
\hline Ti32Hi18Ni5Cu45 & 1100 & $\begin{array}{c}\text { Bulk } \\
\text { Ribbon } \\
\text { Ribbon, } 570^{\circ} \mathrm{C}, 1^{\text {* }}\end{array}$ & $\begin{array}{l}\text { no } M T \\
\text { no } M T \\
\text { no } M T\end{array}$ & & A \\
\hline
\end{tabular}

Following the so-called " golden rules », we have substituted the $\mathrm{B}$ elements $(\mathrm{Ni}$ and $\mathrm{Cu}$ ) from the two series $\mathrm{TiHfNiCu}$ and $\mathrm{TiZrNiCu}$, by small amount of new elements ( $\mathrm{Ag}, \mathrm{Al}, \mathrm{Co}, \mathrm{Pd}$ ) to stay as closed as possible from the reference SMA compositions. From table 2, it is seen that a simple increase of the number of the constituent elements for the same "A:B"=50:50 ratio does not allow to produce the ribbons in a totally amorphous structural state. Despite the presence of the crystalline phase no martensite transformation has been detected by DSC in the $\left(-170^{\circ} \mathrm{C},+400^{\circ} \mathrm{C}\right)$ range in the as received ribbons. Moreover, excepted for $\mathrm{Ti}_{48} \mathrm{Zr}_{2} \mathrm{Ni}_{23} \mathrm{Pd}_{2} \mathrm{Cu}_{23} \mathrm{Ag}_{2}$, simple $\left\{25^{\circ} \mathrm{C} \rightarrow\left(570^{\circ} \mathrm{C}-600^{\circ} \mathrm{C}\right), 1 \mathrm{mn}\right\}$ crystallisation step is not sufficient to restore the martensite transformation in the ribbons and appropriate heat treatment regimes are requested. Some examples of these thermal treatments are reported in table 2 .

Figure 5 shows an example of the first heating run in the simple $\left\{25^{\circ} \mathrm{C}->\left(570^{\circ} \mathrm{C}-600^{\circ} \mathrm{C}\right), 1^{\prime}\right\}$ crystallisation step. All ribbons containing the amorphous structure component show a specific heat flow variation as follow: a curvature around $\mathrm{T}_{\mathrm{g}}$ and a strong exothermal one or two peaks above the $\mathrm{T}_{\mathrm{X}}$ insert. The first feature corresponds to the glass transition temperature, the second occurs due to the crystallisation process of the amorphous structure component and/or secondary particles formation. 
Table 2 : Some thermodynamic and structural characteristics for the $A: B=50: 50$ series alloys.

\begin{tabular}{|c|c|c|c|c|c|}
\hline Nominal composition & Quenching $\mathrm{T}^{\circ} \mathrm{C}$ & Condition & $\mathrm{Mp}^{\circ} \mathrm{C}$ & $\mathrm{Ap}{ }^{\circ} \mathrm{C}$ & Structure as-cast \\
\hline Ti47Hf3Ni23Pd2Cu24.5Ag0.5 & 1320 & $\begin{array}{l}\text { Bulk } 950^{\circ}, \text { I hour } \\
\text { Ribbon as-cast } \\
\text { ThT }: 800^{\circ} \mathrm{C}, 3 \mathrm{~h}\end{array}$ & $\begin{array}{c}-60 \\
\text { no MT } \\
-84\end{array}$ & $\begin{array}{l}-23 \\
-68\end{array}$ & $A+B 2$ \\
\hline Ti48Zr2Ni23Pd2Cu23Ag2 & 1280 & $\begin{array}{l}\text { Bulk as-cast } \\
\text { Tht }: 950^{\circ}, 1 \mathrm{~h} \\
\text { Ribbon as-cast } \\
\text { ThT }: 800^{\circ}, 3 \mathrm{~h}\end{array}$ & $\begin{array}{c}-85 \\
-63 \\
\text { no MT } \\
-60 /-65\end{array}$ & $\begin{array}{l}-69 \\
-5 \\
-50 \\
\end{array}$ & $\begin{array}{c}\mathrm{A}+\mathrm{B} 2 \\
\mathrm{~B} 2+\mathrm{Ti} 2 \mathrm{Ni}+\mathrm{B} 19\end{array}$ \\
\hline Ti48Zr2Ni20Cu25Co5 & 1310 & $\begin{array}{c}\text { Bulk as-cast } \\
\text { Tht }: 950^{\circ}, 1 \mathrm{~h} \\
\text { Ribbon as-cast } \\
\text { Tht }: 585^{\circ}, 5 \mathrm{~h} \\
800^{\circ}, 3 \mathrm{~h}\end{array}$ & $\begin{array}{c}-122 \\
-145 \\
\text { no MT } \\
-158 \\
\text { no MT }\end{array}$ & $\begin{array}{l}-108 \\
-133 \\
-137\end{array}$ & $\begin{array}{c}\text { B2+ Particules } \\
\text { A+B2 } \\
\text { B2+Ti2Ni+B19 } \\
\text { B2+Ti2Ni+B19 }\end{array}$ \\
\hline
\end{tabular}

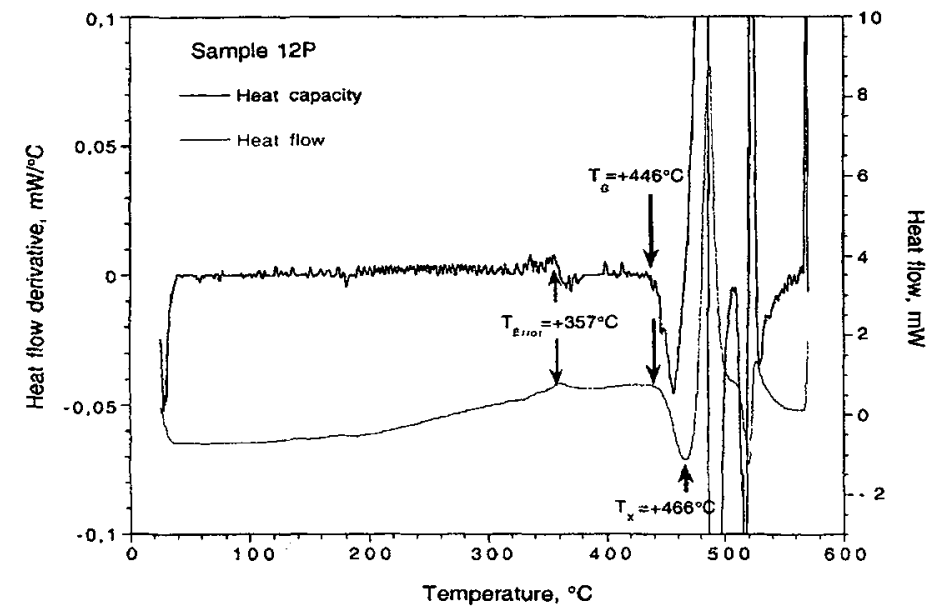

Figure 5: Typical heat flow variation during the main transformation from the amorphous to crystalline state in the simple crystallisation step $\left\{25^{\circ} \mathrm{C}=>(570 \div 600)^{\circ} \mathrm{C}, 1 \mathrm{~min}\right\}$ for a $\mathrm{Ti} 48 \mathrm{Zr} 7 \mathrm{Ni} 18 \mathrm{Cu} 25 \mathrm{Co} 2$ rapidly solidified sample of the "A:B"=5545 series alloys. $T x$ is the crystallisation temperature and $\mathrm{Tg}$ the vitreous transition.

Several heat treatment regimes have been used for the restoration of the shape memory property of the multicomponent alloys in the initial amorphous state (see Tables 1 and 2 for representative alloys). The logic of the heat treatment regimes chosen for the crystallisation and microstructure formation may be easily understood taking into account the following factors. Previous experience with the reference binary $\mathrm{Ti}-\mathrm{Ni}$ and ternary TiNiMe alloys in the bulk material showed that the most dramatic changes in the material microstructure happen after treatment at intermediate temperatures around the recrystallisation temperature. The temperature range of the Ti2 $\mathrm{Ni}$-type particles formation is usually wide (from room temperature up to $>1200^{\circ} \mathrm{C}$ ), while the $\mathrm{Ni}$-rich particles $\left(\mathrm{Ti}_{3} \mathrm{Ni}_{4}, \mathrm{Ti}_{2} \mathrm{Ni}_{3}, \mathrm{TiNi}_{3}\right.$ ) appear at intermediate temperatures below approximately $750^{\circ} \mathrm{C}$. Thus, heat treatment regimes at high temperatures $\left(900^{\circ} \mathrm{C}, 16 \mathrm{~h}\right.$ and $700 \rightarrow 900^{\circ} \mathrm{C}$ ) are oriented on production of the b.c.c. phase (probably, with some amount of the Ti2 $2 \mathrm{Ni}$-type particles). The aim of the regime ageing temperature (585$600)^{\circ} \mathrm{C}$, which corresponds to the highest rate of the Ni-rich precipitates nucleation and growth in binary alloy system and also in some multicomponent alloys is, on the one hand, to analyse the structure and composition of the precipitates. On the other hand, it aims to check the effect of particles formation on the martensite transformation temperatures and parameters of the functional properties. The evolution of the transforming b.c.c. phase microstructure and chemical composition may occur due to consequent change of the precipitates like $\mathrm{Ti}_{3} \mathrm{Ni}_{4}-\mathrm{Ti}_{2} \mathrm{Ni}_{3}-\mathrm{TiNi} 3$. The details of these thermal treatment will be discussed elsewhere.

Another series of multicomponents alloys ( $\mathrm{TiZr} / \mathrm{Hf}):(\mathrm{NiCuAg} / \mathrm{Co})$ based on the stoechiometry $55: 45$, has permitted the production of smooth fully amorphous ribbons. The simple crystallization step $\left\{25^{\circ} \mathrm{C} \rightarrow\left(570^{\circ} \mathrm{C}-600^{\circ} \mathrm{C}\right), 1 \mathrm{mn}\right\}$ is again not sufficient to restore the martensite transformation in the ribbons but nevertheless, some of them exhibit a good Shape Memory behaviour after bending in liquid Nitrogen. Recrystallisation of these specimen is on progress. 


\section{CONCLUSION}

1. We developed a technological path for the production of multicomponent shape memory alloys initially in the amorphous state. New multicomponent alloys of the "A:B" type general series have been systematically produced by means of induction melting prior to casting and rapid solidification (Planar flow casting technique). The alloys with the following constituent " $\mathrm{A}=(\mathrm{Ti}, \mathrm{Zr}, \mathrm{Hf}, \mathrm{Be}, \mathrm{Y})$ and $" \mathrm{~B} "=(\mathrm{Ni}$, $\mathrm{Cu}, \mathrm{Co}, \mathrm{Pd}, \mathrm{Ag}, \mathrm{Al}, \mathrm{Be}, \mathrm{Y}$ ) have been examined (for $\mathrm{Be}$ and $\mathrm{Y}$ substitution see [10]).

2. The chemical compositions of the developed alloys were optimised on a set of selection rules including the "golden rules" for bulk amorphous material.

3. For TiNiCu and TiHfNiCu, a summary is given in a form of the diagrams of the B2 $\Leftrightarrow=\mathrm{B} 19<\Rightarrow \mathrm{B} 19^{\prime}$ martensite transformations. It is stated that the $\mathrm{B} 2 \Leftrightarrow \Rightarrow \mathrm{B} 19^{\prime}$ transformation sequence changes to the $\mathrm{B} 2<=>\mathrm{B} 19<=>\mathrm{B} 19^{\prime}$ transformation sequence at smaller content of $\mathrm{Cu}$, on substitution of Ti by $\mathrm{Hf}$.

4. It is established that the "A:B"-type shape memory alloys with the "A:B" ratio varied as 45:55, 50:50 and 55:45 can be easily obtained in the amorphous or the mixture (amorphoustcrystalline) component states by the planar-flow casting technique.

5. Practically all developed amorphous alloys can be easily crystallised in the b.c.c. phase in the simple $\left\{25^{\circ} \mathrm{C}->\left(570^{\circ} \mathrm{C}-600^{\circ} \mathrm{C}\right), 1^{\prime}\right\}$ crystallisation step or during subsequent heat treatments in the $(400 \div 900)^{\circ} \mathrm{C}$ temperature range. They may undergo the reversible martensite transformation in the $\left(-150^{\circ} \mathrm{C}-+300^{\circ} \mathrm{C}\right)$ temperature range as a function of the alloy composition and microstructure condition. Several heat treatment routes have been performed in order to find the optimised structural state appropriate both for the reversible martensite transformation and good mechanical/functional properties. Smooth increase of the martensite transformation temperature with the ageing temperature has been found supporting the important role of the mean grain size in position of the MT onset.

6. Microstructural investigation by TEM is being performed. Injection casting experiments are being carried out in order to determine the glass forming ability of the most promising compositions for production of bulk amorphous precursors.

\section{Acknowledgements}

We are pleased to acknowledge the Centre National de la Recherche Scientifique for the Invited Senior Scientist Position granted to Pr. V. Kolomytsev and the Science and Technology Centre of Ukraine for its support.

\section{References}

1. A. Inoue, High Strength Bulk Amorphous Alloys with Low Critical Cooling Rates (Overview), Materials Transactions, JM, 36, 7 (1995), 866-875.

2. A. Inoue Acta Mater. 48 (2000) 279-306

3. E.Cesari, J. Van Humbeeck,, V.Kolomytsev, V.Lobodyuk, N.Matveeva, "Parameters of Martensite Transformation and Structural State in rapidly quenched Ti35Nil5Cu shape memory alloys", J.Phys., IV FRANCE, 7 (1997) C5-197

4. V. Kolomytsev, A. Pasko, R. Portier, P. Ochin, A. Seerneels, W. Van Moorleghem, E. Cesari, C. Segui, "The Ti-Ni-Me and $\mathrm{Cu}-\mathrm{Al}-\mathrm{Me}$ melt spun shape memory ribbons: relation between the microstructure and functional properties, SMM 99, Japan (1999).

5. Project STCU-453 "Research and development of the multicomponent shape memory alloys by means of thin film and ultrasonic technology"

6. V. Kolomytsev, Scripta Metallurgica 31, 10 (1994) 1415.

7. V. Kolomytsev, "Trend across periodic table in the effect of alloying by transition metal on martensite transformation temperatures in compound TiNi", Proc. SMM-94, 1994, 136-143.

8. V.Kolomytsev, Structural Phase Transformations in the Transition Metal TiNi-Me and CuAlMe Alloy Systems, Dr.Sc. Thesis, Kiev, Institute of Metal Physics, 1996.

9. W. Moorleghem, The investigation of new Ni-Ti shape memory alloys with emphasis on their application, Ph.D. Thesis, Kiev, Institute of Metal Physics, 1993.

10. Kolomytsev, M. Babanly, R. Musienko, A. Sezonenko, P. Ochin, A. Dezellus, P. Plaindoux, R. Portier, F. Dalle, P. Vermaut, "Effect of Be and $\mathrm{Y}$ on the martensite transformation parameters in TiNi compounds", this conference. 